\section{PENGARUH PEMBERIAN TERAPI SEFT DAN MENDENGARKAN \\ BACAAN AL-QUR'AN TERHADAP NYERI PASIEN POST OPERASI HERNIA}

“THE EFFECT OF THERAPY SEFT AND

LISTENED TO READINGS AL-QUR'AN AGAINTS THE PATIENTS PAIN RESPONSE POST HERNIA SURGERY"

\author{
Alvin Abdillah*) \\ Merlyna Suryaningsih*) \\ *) Sekolah Tinggi Ilmu Kesehatan (STIKes) \\ Ngudia Husada Madura
}

\section{ABSTRACT}

Hernia postoperative pain is the sensation of pain felt by the patient's postoperative irritation caused by the stimulation of peripheral nerves along due to surgery. From the results of the preliminary study in ward Irna A Hospital Syarifah Ambami Rato Ebu Bangkalan, it is found that the high incidence pain of postoperative hernia. The purpose of this study is to determine the effect before and after therapy SEFT and listen Qur'an in patients with postoperative hernia in Irna ward A Hospital Syarifah Ambami Rato Ebu Bangkalan.

The study design used "pre-experimental" approach with one-group pre-post test design. Population estimates is taken 15 respondents and the samples were taken by 13 respondents. Sampling technique was using a quota sampling independent variables of Research is therapeutic SEFT and listen Qur'an and the dependent variable of research was pain of postoperative hernia. While the data collection tool used observation sheets with numerical scale of 0-10 with Wilcoxon statistical tests.

The results showed that pain of postoperative hernia on the respondent before therapy was given SEFT and listening reading the Qur'an 8 (61.5\%) of respondents with a mean of 3.08 experiencing severe pain, while the therapy was given after SEFT theraphy and listening to reading AlQur'an 6 ( $46.1 \%)$ of respondents with a mean of 1.23 experiencing mild pain. Based on the results statistically using the Wilcoxon, showed P Value: 0,002 < : 0.05, which means there were significant pain of postoperative hernia before and after given therapy listening to the recitation of Al-Qur'an.

Based on the above results, that therapeutic SEFT and listen Qur'an is very effective in lowering pain of postoperative hernia. So when experiencing pain of postoperative hernia, respondents are expected to use the therapy SEFT and reading Al-Qur'an as a non-pharmacological solutions.

Keywords: Hernia, Murrotal, SEFT, Pain

Correspondence : Alvin Abdillah, Jl. R.E. Martadinata Bangkalan, Indonesia.

\section{PENDAHULUAN}

"Hernia merupakan penonjolan sebuah organ, jaringan atau struktur melewati dinding rongga yang secara normal memang berisi bagian-bagian tersebut".(Muttaqin, 2011). Sedangkan menurut Black \& Hawks, (2009) "Hernia merupakan penyakit yang dapat menyerang semua umur baik anak, dewasa maupun lansia yang ditandai dengan adanya penonjolan".

Beberapa kondisi yang dapat menyebabkan hernia antara lain mengejan, menangis, mengangkat benda berat atau barang yang berat. Sementara benjolan tersebut dapat menghilang jika penderita istirahat atau berbaring terlentang (Ignatavicius \& Workman, 2006).

Penatalaksaan tindakan yang paling umum dilakukan untuk memperbaiki 
kondisi tersebut ialah dengan pembedahan (herniotomi). Namun tindakan pembedahan dengan malukan penyayatan dapat menyebabkan kondisi trauma pada klien yang dapat menimbulkan gejala nyeri. Nyeri merupakan salah satu masalah yang sering dikeluhkan pasien setelah menjalani tindakan pembedahan. "Pembedahan merupakan suatu peristiwa yang bersifat bifasik terhadap tubuh manusia yang berimplikasi pada pengelolaan nyeri. Lama waktu pemulihan pasien post operasi normalnya terjadi hanya dalam satu sampai dua jam” (Potter \& Perry, 2005). Waktu rata-rata pemulihan pasien post operasi berkisar antara 72,45 menit, dan pasien akan merasakan nyeri yang hebat rata-rata pada dua jam pertama setelah operasi karena pengaruh obat anastesi sudah hilang, dan pasien sudah dipindahkan keruang perawatan (Mulyono, 2008).

Persepsi nyeri yang dirasakan oleh pasien post operasi hernia merupakan rasa ketidaknyamanan yang ditimbulkan karena adanya suatu cedera fisik yang dirasakan sepanjang saraf perifer. Rangsangan tersebut dapat berupa rangsangan listrik, mekanik maupun kimiawi (Berman \& Snyder, 2011). Sayatan pada kulit abdomen merupakan faktor pencetus nyeri yang menstimulasi rangsangan nociceptor.

Berdasarkan studi pendahuluan yang dilakukan pada tanggal 11 Desember 2017 di RSUD Syamrabu Bangkalan selama tiga bulan terakhir yaitu bulan September, Oktober, November berjumlah 44 pasien post operasi hernia. Didapatkan pada 10 pasien post operasi hernia menggunakan kuesioner lembar observasi nyeri, yaitu 2 (20\%) mengalami nyeri skala ringan, 3 $(30 \%)$ mengalami nyeri skala sedang, 5 $(50 \%)$ mengalami nyeri skala berat. Hal ini menunjukkan tingginya nyeri Post operasi hernia yang dirasakan pasien.

Mengontrol nyeri adalah hal yang sangat penting bagi pasien untuk mengembalikan fungsi dan meningkatkan kenyamanan (Potter \& Perry, 2012). Penanganan nyeri dapat dilakukan dengan berbagai macam cara yaitu secara farmakologis dan non farmakologis. Secara farmakologis dapat dengan pemberian obatobatan analgesik sedangkan secara non farmakologis dapat dilakukan dengan cara kompres dingin dan panas, distraksi, relaksasi nafas dalam imajinasi terbimbing, hipnosis, terapi music, massage, perubahan posisi tubuh, terapi SEFT dan terapi mendengarkan bacaan al-qur'an. (Andarmoyo, 2013).

Salah satu penatalaksanaan nyeri pada pasien post operasi yang dapat digunakan adalah terapi Spiritual Emosional Freedom Technique (SEFT), terapi ini sangat mudah sekali di praktekkan. Hanya, dengan ketukan ringan (tapping) pada 18 titik di sepanjang 12 energi tubuh, dan meiliki efek penyembuhan yang sangat cepat, SEFT juga dapat mengatasi masalah fisik maupun emosi. (Zainudin, 2008) Sedangkan terapi dengan mendengarkan bacaan Al-quran memiliki pengaruh positif bagi pendengarnya dan pembacanya (Widayarti, 2011). Terapi bacaan Al Qur'an dapat mengurangi rasa sakit post operasi, diperkuat dari pernyataan Baihaqi Tholhah bin Mussarif berkata "Aku pernah mendengar bahwa ketika dibacakan Al-quran kepada orang yang sedang sakit niscaya sakitnya akan berkurang" (Al Durr Al Manstur, dalam Elzaky, 2011). Sesuai dengan hadist Rosululloh SAW yang bersabda " Sebaikbaik obat adalah Al-quran" (HR. Ibnu Majah, dalam 'Izzat \& 'Arif, 2011). Melihat pentingnya terapi nonfarmakologi yang digunakan untuk mengatasi nyeri Post operasi hernia seperti terapi SEFT dan mendengarkan bacaan ALQur'an, pasien harus mempunyai kesadaran bahwasannya terapi ini mengandung unsurunsur manusia yang dapat menurunkan hormon hormon stres, seperti hormon melatonin, hormon oksitosin, hormon adrenal, hormon seks yang dapat memberikan rasa tenang dan menghilangkan rasa takut, cemas dan tegang. Berdasarkan latar belakang tersebut peneliti tertarik untuk meneliti "Pengaruh Terapi SEFT dan mendengarkan bacaan AL-Quran melalui media audio terhadap penurunan Respons Nyeri Pasien Post Operasi Hernia di Ruang Irna A RSUD Syamrabu (Syamrabu) Bangkalan”.

\section{METODE PENELITIAN}

Penelitian ini menggunakan praeksperimental dengan model one group pre-post test design yaitu mencari hubungan sebab akibat pada kelompok subjek saja. Variabel independen pada penelitian ini adalah terapi SEFT yang dikombinasikan dengan mendengarkan bacaan Al-Qur'an. Sedangkan variabel 
dependen pada penelitian ini adalah skala Nyeri post operasi hernia. Populasi yang digunakan adalah pasien post operasi hernia yang mengalami nyeri di Ruang Irna A RSUD Syamrabu Bangkalan dengan jumlah sampel 13 responden. Tehnik sampling yang digunakan dalam penelitian ini adalah quota Sampling.

\section{HASIL PENELITIAN}

\section{Data Umum}

Karakteristik Responden berdasarkan usia di ruang irna A RSUD Syamrabu Bangkalan.

Tabel 4.1 Distribusi Frekuensi Responden Berdasarkan Usia di ruang irna A RSUD Syamrabu Bangkalan pada bulan Mei-Juni 2018

\begin{tabular}{ccc}
\hline Usia & Frekuensi & $\begin{array}{c}\text { Persentase } \\
(\%)\end{array}$ \\
\hline $30-45$ & 7 & 53,8 \\
$46-60$ & 6 & 46,2 \\
\hline Total & 13 & 100 \\
\hline
\end{tabular}

Sumber Data Primer 2018

Berdasarkan tabel 4.1 diatas didapatkan hasil bahwa sebagian besar responden berusia 30-45 tahun yaitu sebanyak 7 orang $(53,8 \%)$ pasien post operasi hernia di ruang irna A RSUD Syamrabu Bangkalan.

Karekteristik Responden berdasarkan pekerjaan di ruang irna A RSUD Syamrabu Bangkalan.

Tabel 4.2 Distribusi Frekuensi Responden Berdasarkan pekerjaan di ruang irna A RSUD Syamrabu pada bulan Mei-Juni 2018.

\begin{tabular}{ccc}
\hline Pekerjaan & Frekuensi & $\begin{array}{c}\text { Persentase } \\
(\%)\end{array}$ \\
\hline Kuli & & \\
bangunan & 5 & 38,4 \\
Petani & 3 & 23,1 \\
wiraswasta & 3 & 23,1 \\
Supir & 2 & 15,4 \\
\hline Total & 13 & 100 \\
\hline \multicolumn{2}{l}{ Sumber Data Primer 2018}
\end{tabular}

Berdasarkan tabel 4.2 diatas didapatkan hasil bahwa hampir setengahnya 5 orang $(38,4 \%)$ pekerjaan responden kuli bangunan di ruang irna A RSUD Syamrabu Bangkalan.

Karakteristik Responden berdasarkan jenis kelamin di ruang irna A RSUD Syamrabu Bangkalan.

Tabel 4.3 Distribusi frekuensi Responden Berdasarkan jenis kelamin di ruang irna A RSUD Syamrabu Bangkalan pada bulan Mei-Juni 2018

\begin{tabular}{ccc}
\hline $\begin{array}{c}\text { Jenis } \\
\text { kelamin }\end{array}$ & Frekuensi & $\begin{array}{c}\text { Persentase } \\
(\%)\end{array}$ \\
\hline Laki-laki & 12 & 92,3 \\
Perempuan & 1 & 7,7 \\
\hline Total & 13 & 100 \\
\hline
\end{tabular}

Sumber Data Primer 2018

Berdasarkan tabel 4.3 diatas didapatkan hasil bahwa hampir seluruhnya responden berjenis kelamin laki-laki yaitu sebanyak 12 orang $(92,3 \%)$ pasien post operasi hernia di ruang ruang irna A RSUD Syamrabu Bangkalan.

\section{Data Khusus}

Pada data khusus akan disajikan hasil pengumpulan data, meliputi distribusi frekuensi responden berdasarkan tingkat nyeri post operasi hernia.

Nyeri Post Operasi Hernia Sebelum Diberikan Terapi SEFT dan Bacaan AlQur'an

Tabel 4.4 Nyeri post operasi hernia sebelum diberikan terapi SEFT dan mendengarkan bacaan al-qur'an di ruang irna A RSUD Syamrabu Bangkalan pada bulan Mei-Juni 2018.

\begin{tabular}{ccc}
\hline Responden & $\begin{array}{c}\text { Skala } \\
\text { Nyeri }\end{array}$ & Kategori \\
\hline 1 & 10 & Sangat Berat \\
2 & 4 & Sedang \\
3 & 9 & Berat \\
4 & 10 & Sangat Berat \\
5 & 8 & Berat \\
6 & 7 & Berat \\
7 & 9 & Berat
\end{tabular}




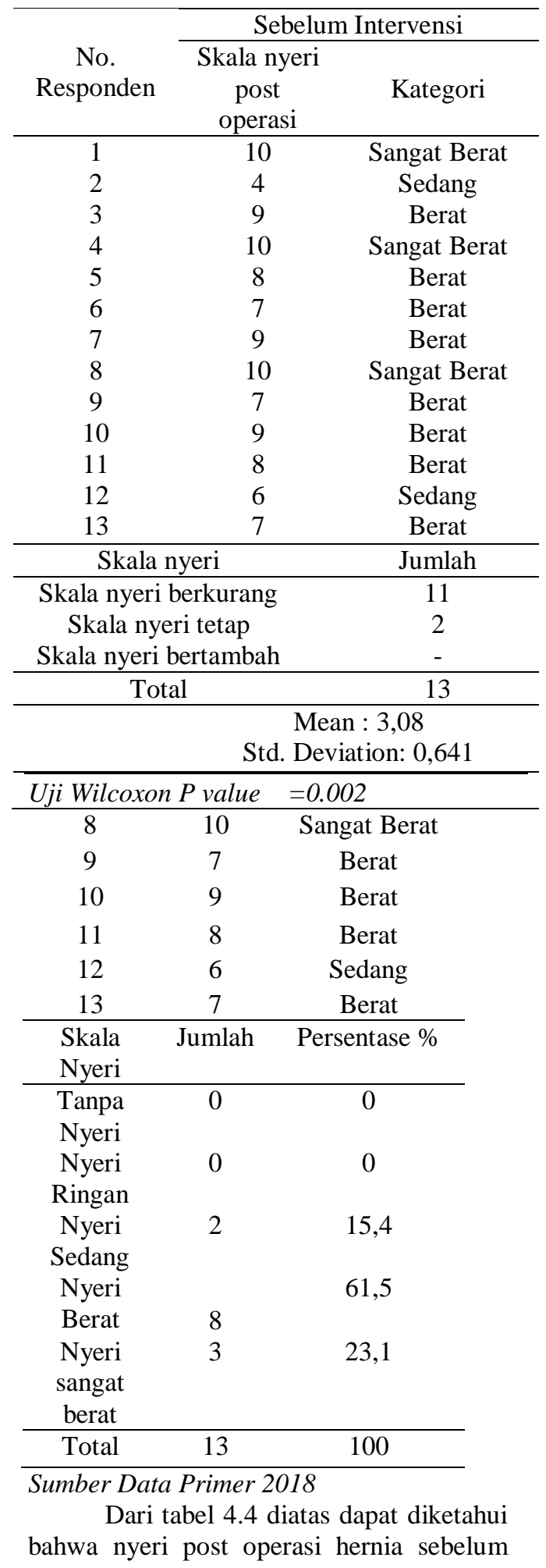

diberikan terapi SEFT dan bacaan Alqur'an di ruang irna A RSUD Syamrabu Bangkalan sebagian besar dari responden mengalami nyeri berat yaitu $8 \quad(61,5 \%)$ pasien.

\section{Nyeri Post Operasi Sesudah Diberikan Terapi SEFT dan Bacaan Al-Qur'an}

Tabel 4.5 Nyeri post operasi hernia sesudah diberikan terapi SEFT dan mendengarkan bacaan al-qur'an di ruang irna A RSUD Syamrabu Bangkalan pada bulan Mei-Juni 2018.

Sumber Data Primer 2018

Dari tabel 4.5 diatas dapat diketahui bahwa nyeri post operasi hernia sesudah diberikan terapi SEFT dan bacaan Al-qur'an di ruang irna A RSUD Syamrabu Bangkalan hampir setengahnya mengalami nyeri ringan sebanyak $6(46,1 \%)$ pasien.

Pengaruh Skala Nyeri Post Operasi Hernia Sebelum dan Sesudah Diberikan Terapi SEFT dan Mendengarkan Bacaan Al-Qur'an

Tabel 4.6 Nyeri post operasi hernia sebelum dan sesudah diberikan terapi SEFT dan mendengarkan bacaan Al-qur'an di ruang irna A RSUD Syamrabu Bangkalan pada bulan Mei-Juni 2018

Sumber data primer 2018

\begin{tabular}{|c|c|c|}
\hline Responden & $\begin{array}{l}\text { Skala } \\
\text { Nyeri }\end{array}$ & Kategori \\
\hline 1 & 3 & Ringan \\
\hline 2 & 0 & Tanpa nyeri \\
\hline 3 & 2 & Ringan \\
\hline 4 & 5 & Sedang \\
\hline 5 & 3 & Ringan \\
\hline 6 & 7 & Berat \\
\hline 7 & 9 & Berat \\
\hline 8 & 5 & Sedang \\
\hline 9 & 1 & Ringan \\
\hline 10 & 2 & Ringan \\
\hline 11 & 3 & Ringan \\
\hline 12 & 0 & Tanpa nyeri \\
\hline 13 & 0 & Tanpa nyeri \\
\hline $\begin{array}{l}\text { Skala } \\
\text { Nyeri }\end{array}$ & Jumlah & $\begin{array}{c}\text { Persentase } \\
\%\end{array}$ \\
\hline $\begin{array}{l}\text { Tanpa } \\
\text { Nyeri }\end{array}$ & 3 & 23,1 \\
\hline $\begin{array}{l}\text { Nyeri } \\
\text { Ringan }\end{array}$ & 6 & 46,1 \\
\hline $\begin{array}{l}\text { Nyeri } \\
\text { Sedang }\end{array}$ & 2 & 15,4 \\
\hline $\begin{array}{l}\text { Nyeri } \\
\text { Berat }\end{array}$ & 2 & 15,4 \\
\hline Total & 13 & 100 \\
\hline
\end{tabular}


Sesudah Intervensi

Dari tabel 4.6 diatas dapat diketahui bahwa nyeri post operasi hernia sebelum diberikan terapi SEFT dan bacaan al-qur'an di ruang Irna A RSUD Syamrabu Bangkalan se

bagian besar dari responden mengalami nyeri berat yaitu 8 orang $(61,5 \%)$ pasien dengan mean :3.08. Sedangkan nyeri post operasi hernia sesudah diberikan terapi bacaan al-qur'an hampir setengahnya mengalami nyeri ringan sebanyak 6 orang $(46,1 \%)$ pasien dengan mean: 1,23.

Dari hasil analisa uji statistik dengan menggunakan Uji wilcoxon diperoleh $P$ Value sebesar $0,002<\alpha(0,05)$ sehingga $\mathrm{H} 0$ ditolak dan $\mathrm{H} 1$ diterima yang berarti ada pengaruh skala nyeri post operasi hernia antara sebelum dan sesu dah diberikan terapi SEFT dan mendengarkan bacaan Al-qur'an di ruang irna A RSUD Syamrabu Bangkalan.

\section{PEMBAHASAN}

\section{Skala Nyeri Post Hernia Sebelum \\ Diberikan Terapi SEFT dan \\ Mendengarkan Bacaan Al-Qur'an di \\ Irna A RSUD Syamrabu Bangkalan.}

Berdasarkan penelitian tentang nyeri hernia sebelum diberikan terapi SEFT dan mendengarkan bacaan AlQur'an pada pasien di Irna A RSUD Syamrabu Bangkalan sebanyak 13 responden menunjukkan bahwa sebagian besar mengalami nyeri berat sebanyak 8 $(61,5 \%)$ responden. Nyeri post operasi hernia yang dialami responden terjadi karena adanya perlukaan pada bagian abdomen pasien sementara efek anastesi sudah mengilang.

Jitoko (2010) menjelaskan bahwa skala nyeri yang dirasakan pasien post operasi apendik hari pertama yang belum mendapatkan terapi analgesik skala nyerinya dapat mencapai nyeri berat, dalam hal ini persepsi individu juga berpengaruh terhapat respon nyeri yang mereka rasakan.

Nyeri hernia disebabkan oleh rangsangan stimulus saraf selama tindakan pembedahan (Aasvang, Hansen \&Kehlet, 2008). Nyeri dirasakan mulai hari pertama sampai ketiga paska operasi, mulai dari nyeri skala ringan sedang

sampai berat tergantung pada jenis atau luasnya pembedahan (Coll \& Ameen, 2006).

\section{Skala Nyeri Post Hernia Sesudah Diberikan Terapi SEFT dan Mendengarkan Bacaan Al-Qur'an di Irna A RSUD Syamrabu Bangkalan. \\ Berdasarkan hasil penelitian} tentang nyeri hernia sesudah diberikan terapi SEFT dan mendengarkan AlQur'an pada pasien yang mengalami nyeri hernia di Irna A RSUD Syamrabu Bangkalan menunjukkan bahwa hampir setengah responden mengalami penurunan ke skala nyeri ringan yaitu sebanyak 6 $(46,1 \%)$ pasien. Penurunan skala nyeri hernia yang dialami responden sesudah diberikan terapi SEFT dan mendengarkan bacaan Al-Qur'an selama 3x15 menit. Menurut responden, ketika diberikan terapi SEFT dan mendengarkan bacaan Al-Qur'an individu akan merasakan nyaman dan rileks karena sel-sel tubuh bergerak teratur kearah perbaikan, sehingga nyeri berkurang dan proses penyembuhan pasien berlangsung lebih cepat.

Intervensi SEFT terbukti mampu secara signifikan menurunkan intensitas nyeri post operasi. Hal ini dapat dilihat dari hasil penurunan intensitas nyeri pada kelompok intervensi. SEFT merupakan terapi pengobatan yang menggabungkan sistem energi tubuh 
dengan terapi spiritual dengan menggunakan metode tapping pada beberapa titik tertentu pada tubuh, cara kerja SEFT sama dengan akupunktur dan akupresur, Ketiganya bekerja dengan cara merangsang titik kunci pada sepanjang 12 jalur energy tubuh, Perbedaannya teknik SEFT menggunakan unsur spiritual, cara yang digunakan lebih aman, lebih cepat, lebih mudah, dan lebih sederhana (Zainuddin, 2008) Aspek spiritual subyek disentuh dengan membimbing subyek mengucapkan kalimat kepasrahan dan keikhlasan yang akhirnya membimbing mereka dalam kondisi khusyu'. Kondisi ini dianalogikan sebagai kondisi meditatif yang dapat mempengaruhi perubahan fisiologis seseorang. (zainudin, 2008)

Tindakan tapping akan mempengaruhi sistem saraf pusat. jika pusat otak yang lebih tinggi teraktivasi maka gerbang di spinal cord akan menutup, sehingga sensasi nyeri tidak akan sampai ke pusat otak dan tidak akan diinterpretasikan sebagai nyeri. (zainudin, 2008), sedangan Menurut Alkahel (2011) mendengarkan Al-Qur'an akan memberikan efek ketenangan sebesar $65 \%$ serta menghilangkan nyeri akibat pembedahan. Upaya yang dilakukan untuk mengaktifkan energy positif didalam tubuh memalui ketukan ringan dan stimulasi gelombang suara.

Terapi SEFT yang dikombinasikan dengan mendengarkan bacaan Al-Qur'an terbukti dapat melepaskan endorphin dengan pengaktifan sel-sel tubuh melalui getaran suara yang ditangkap oleh tubuh menuju pusat reseptor nyeri di otak sehingga menimbulakn rasa ketenangan.

Sesudah diberikan terapi SEFT dan mendengarkan bacaan Al-Qur'an didapatkan mean skala nyeri hernia 1.23 dan terjadi penurunan skala nyeri yang signifikan. Hasil penelitian juga menunjukkan sebagian kecil responden yang tidak mengalami penurunan maupun peningkatan melainkan tetap yaitu 2 $(15,4 \%)$ responden . Hal ini dikarenakan responden ketika dilakukan pemberian terapi SEFT dan mendengarkan bacaan Al-Qur'an, responden kurang konsentrasi dan tidak rileks. Hal ini didukung dengan teori Izzat \& Arif (2011) bahwa dengan membaca Al-Qur'an atau mendengarkan bacaan Al-Qur'an dapat meningkatkan rasa tenang meningkatkan kesembuhan fisik serta mengurangi ketegangan secara spontan.

Hampir setengahnya $6 \quad(46,1 \%)$ responden mengalami penurunan ke skala nyeri ringan. Hal ini dikarenakan responden konsentrasi dan kooperatif pada pelaksanaan terapi SEFT dan mendengarkan bacaan Al-Qur'an. Hal ini diperkuat oleh Qadri (2003) bahwa sel tubuh yang sakit akan diperbaiki oleh gelombang suara yang masuk ke dalam sel sehingga sel tersebut menjadi teratur.

Sebagian kecil $3 \quad(23,1 \%)$ responden mengalami penurunan ke skala tidak nyeri. Hal ini dikarenakan responden konsentrasinya penuh, rileks dan nyaman ketika diberikan terapi SEFT dan bacaan Al-Qur'an dan setiap responden memiliki ambang persepsi nyeri yang berbeda-beda. Hal ini didukung dengan teori Al-Kahel (2011) bahwa mendengarkan bacaan Al-Qur'an dapat memberikan efek ketenangan sebesar $65 \%$, getaran gelombangan suara ini akan masuk ke dalam tubuh dan mengubah partikel cairan tubuh untuk merangsang gelombang otak mengaktifkan jalur tekanan nyeri. Jalur ini akan memutus syaraf penghantar nyeri sehingga memberikan efek ketenangan dan mengurangi nyeri.

Dan sebagian kecil juga mengalami penurunan ke skala nyeri sedang $2(15,4 \%)$ responden dan ke skala nyeri berat $2(15,4 \%)$ responden. Hal ini disebabkan karna responden kurang konsentrasi dalam mendengarkan terapi bacaan Al-Qur'an. Hasil wawancara dengan responden didapatkan bahwa responden tidak bisa fokus dan malas untuk mengikuti serta menganalisa terapi mendengarkan bacaan Al-Qur'an tersebut. Padahal, untuk merubah perilaku dibutuhkan niat dari diri seseorang untuk bertindak maju ke arah yang lebih baik seperti yang dikemukakan Notoatmodjo (2003) bahwa perilaku bertitik tolak dari niat seseorang untuk bertindak sehubungan dengan kesehatan atau perawatan kesehatannya (behaviour intention).

Al-Qur'an merupakan wahyu Allah SWT yang telah memiliki banyak manfaat baik untuk kesembuhan penyakit baik jasmani maupun rohani bagi orang yang membaca maupu mendengarkannya. Hal ini ditegaskan berdasarkan sabda 
Rasulullah SAW "berobatlah kalian dengan madu dan Al-Qur'an" (Izzat \& Arif, 2011). Al-Qur'an telah lama dikenal sebagai metode pengobatan. Terapi sangat diharapakan menjadi salah satu terapi komplementer pilihan utama.

Terapi Al-Qur'an dapat dilakukan dengan cara membaca, dan mendengarkannya dengan berdekatan. (Asman, 2008). Membaca dan mendengarkan Al- Qur'an akan dapat memperoleh kesembuhan dan ketenangan terutama jika Al-Qur'an dibacakan pada orang yang sedang sakit, manfaatnya selain memperoleh kesembuhan juga dapat membawa rahmat (Kementerian Agama, 2011). Dengan mendengarkan bacaan Al-Qur'an sebanyak 3 kali selama 45 menit aliran energy pada bagian sel tubuh yang sakit akan diperbaiki oleh respon getaran suara kemudian sinyalnya dikirimkan ke saraf pusat di otak (AlKahel, 2011).

\section{Pengaruh Skala Nyeri Sebelum dan Sesudah Diberikan Terapi SEFT dan Mendengarkan Bacaan Al-Qur'an di Irna A RSUD Syarifah Ratu Ebu Bangkalan}

Hasil uji statistik dengan menggunakan Uji Wilcoxon Test, didapatkan hasil $P$ Value : 0,002 dengan $\alpha$ 0,05 maka $0,002<0,05$ membuktikan bahwa $\mathrm{H} 1$ diterima sehingga $\mathrm{H} 0$ ditolak yang menunjukkan ada pengaruh sebelum dan sesudah diberikan terapi SEFT dan bacaan Al-Qur'an, hal ini dibuktikan dengan teori (AlKahel, 2011) yaitu "Bagian sel tubuh yang sakit, kemudian diperdengarkan bacaan Al-Qur'an sebanyak 3 kali selama 45 menit, akan mempengaruhi gelombang dalam tubuh dengan cara merespon suara dengan getaran-getaran sinyalnya dikirimkan ke sistem saraf pusat". Sebelum diberikan intervensi sebagian besar ada $8(61,5 \%)$ responden mengalami nyeri berat, sedangkan sesudah diberikan intervensi hampir setengahnya ada $6 \quad(46,1 \%)$ responden mengalami nyeri ringan dengan masing-masing Mean sebelum dan sesudah diberikan terapi mendengarkan bacaan Al-Qur'an yaitu 3.08 dan 1.23. Perbedaan ini terjadi karena dari 13 responden terdapat 11 responden yang mengalami penurunan skala nyeri sesudah diberikan terapi SEFT dan mendengarkan terapi bacaan $\mathrm{Al}-$
Qur'an. Penurunan skala nyeri yang terjadi pada responden menunjukkan adanya pengaruh dari terapi SEFT dan mendengarkan bacaan Al-Qur'an.

Dari hasil penenelitian ini didapatkan bahwa terapi SEFT dan bacaan Al-Qur'an bisa dijadikan sebagai terapi non farmakologi, terapi ini merupakan terapi yang dapat digunakan sebagai obat terutama bagi orang sakit. Saat membaca atau mendengarkan bacaan Al-Qur'an, maka yang membaca atau mendengar terutama akan memperoleh kesembuhan juga membawa rahmat. Sehingga mendengarkan bacaan AlQur'an berpengaruh terhadap kesembuhan terutama mengurangi nyeri hernia, hal ini dibuktikan dengan Penelitian kedokteran Amerika Utara bahwa "dengan membaca Al-Qur'an atau mendengarkannya dapat mengurangi ketegangan susunan saraf secara cepat, sehingga akan menjadi tenang, rileks, dan keluhan-keluhan fisik akan sembuh" (Izzat \& Arif, 2011; Elzaky, 2011). Dibuktikan juga dengan teori Izzat \& Arif (2011) diungkapkan bahwa gelombang cahaya, gelombang radio, dan gelombang suara dapat mempengaruhi sel tubuh pada manusia. Pada prinsipnya getaran sel tubuh akan mengikuti irama dari getaran suara yang masuk ketelinga secara berkelanjutan.

Saat bagian sel tubuh yang sakit, diberikan terapi bacaan Al-Qur'an sebanyak 3 kali selama 15 menit, tubuh akan merespon gelombang tersebut dan sinyalnya akan dikirim ke otak (AlKahel, 2011).

Hal ini didukung oleh penelitian Emoto dari Jepang "bahwa $70 \%$ bagian tubuh manusia adalah air dan medan elektromagnetis serta perubahannya dipengaruhi oleh suara atau bacaan AlQur'an yang diperdengarkan, sehingga berpengaruh terhadap partikel-partikel air didalam tubuh menjadi lebih baik dan teratur". Memberikan terapi bacaan AlQur'an dapat memberikan pahala bagi yang membacanya dan menjadikan kesembuhan bagi yang mendengarkan. Bahkan penelitian Wafi dalam Elzaky (2011) menunjukkan bahwa anak-anak yang mengalami gangguan wicara dapat disembuhkan dengan bacaan Al-Qur'an. 


\section{KESIMPULAN}

Sebagian besar responden di ruang irna A RSUD Syamrabu Bangkalan sebelum diberikan terapi SEFT dan bacaan Al-Qur'an adalah nyeri berat

Hampir setengahnya responden di ruang irna A RSUD Syamrabu Bangkalan sesudah diberikan terapi SEFT dan bacaan Al-Qur'an adalah nyeri ringan

Ada pengaruh skala nyeri post operasi pada responden sebelum dan susudah diberikan terapi SEFT dan mendengarkan bacaan Al-Qur'an di ruang irna A RSUD Syamrabu Bangkalan.

\section{DAFTAR PUSTAKA}

Aasvang, E., Hansen, J., \& Kehlet, H. (2008). Can Preoperative Electrical Nociceptive Stimulation Pain After Groin Herniotomy. Journal of Pain, 940-4.

Alkahel, A. (2011). Al-Quran's the healing. Jakarta:Tarbawi Press

Andarmoyo, S. (2013). Konsep dan proses keperawatan nyeri. Yogyakarta: ArRuzz

Berman, A., \& Snyder, S. J. (2011). Fundamentals of Nursing. Ninth Edition. USA:PEARSON.

Black, J. M., \& Hawks, J. H. (2009). Medical-Surgical Nursing : Clinical Management for Positif Outcomes. USA: Sounders Elsevier.

Coll, A. M., \& Ameen, J. (2006). Profiles of Pain After Day Surgery: Patients Experience of Three Different Operation Types. Issue and Innovation Nursing, 178-187.

Elzaky, J. (2011). Mukjizat Kesehatan Ibadah. Jakarta: Penerbit Zaman.
Ignatavicius, D. D., \& Workman, M. L. (2006). Medical Surgical Nursing : Critical Thinking for Collaborative Care. USA: Elsevier Sounders.

Izzat, A. M., \& 'Arif, M. (2011). Terapi Ayat Al-Qur'an Untuk Kesembuhan : Keajaiban AlQuran Menyembuhan Penyakit. Solo: Kafilah Publishing.

Jitoko, Cama. 2010. Recurrent Abdominal Pain Post Appendectomy - A Rare Case. FRACS, Senior Lecturer-Surgery, Fiji School of Medicine. Correspondence to: Department of Medical Science, Fiji School of Medicine.

Kementerian Agama. (2011). Al-Quran dan Terjemahnya. Semarang : TOHA.

Mulyono. 2008. Hubungan Musik Klasik Dengan Waktu Pemulihan Pasien Post Operasi Seksio Cesaria Dengan Spinal Anestesi di RSUD DR. Moewardi Surakarta. Skripsi S-1 tidak diterbitkan Fakultas Ilmu Kesehatan, Universitas Muhammadiyah Surakarta.

Muttaqin, Arif \& Sari, Kurmala. 2011. Gangguan Gastrointestinal : Aplikasi Asuhan Keperawatan Medikal bedah. Jakarta : Salemba medika.

Notoatmodjo, Soekidjo. 2003. Pendidikan Dan Perilaku Kesehatan. Rineka Cipta. Jakarta.

Potter, P.A \& Perry A.G. 2012. Fundamental of Nursing. Jakarta : EGC

'otter, P.A, Perry, A.G. (2005). Buku Ajar Fundamental Keperawatan : 
Konsep, Proses, dan Praktik.Edisi 4.Volume 2.Alih Bahasa : Renata Komalasari,dkk.

Jakarta:EGC.

Qadri, M. A. (2003). Quranic Therapy Heal Yourself. USA: Islamic Educational Cultural Research Center of North America.

Widaryati (2011). Pengaruh bacaan Al Quran terhadap intensitas kecemasan pasien sindroma coroner akut di RS Hasan Sadikin. Thesis. Universitas Padjajaran.

Zainuddin, A.F. (2008). SEFT For Healing + Succes + Happiness + Greatness. Jakarta: Afzan Publising. 